\title{
Effects of thermal conditioning on the performance of Pocillopora acuta adult coral colonies and their offspring
}

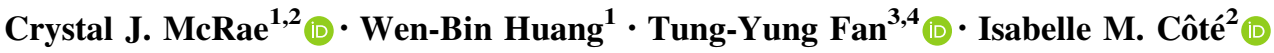

Received: 20 June 2020/Accepted: 25 May 2021/Published online: 21 July 2021

(C) The Author(s) 2021

\begin{abstract}
Ocean warming induced by climate change is the greatest threat to the persistence of coral reefs globally. Given the current rate of ocean warming, there may not be sufficient time for natural acclimation or adaptation by corals. This urgency has led to the exploration of active management techniques aimed at enhancing thermal tolerance in corals. Here, we test the capacity for transgenerational acclimation in the reef-building coral Pocillopora acuta as a means of increasing offspring performance in warmer waters. We exposed coral colonies from a reef influenced by intermittent upwelling and constant warmwater effluent from a nuclear power plant to temperatures that matched $\left(26{ }^{\circ} \mathrm{C}\right)$ or exceeded $\left(29.5{ }^{\circ} \mathrm{C}\right)$ season-specific mean temperatures for three reproductive cycles; offspring were allowed to settle and grow at both temperatures. Heated colonies reproduced significantly earlier in the lunar cycle and produced fewer and smaller planulae. Recruitment was lower at the heated recruitment temperature regardless of parent treatment. Recruit survival did not differ based on parent or recruitment temperature. Recruits from heated parents were smaller and had lower
\end{abstract}

Topic Editor Anastazia Teresa Banaszak

Tung-Yung Fan

tyfan@nmmba.gov.tw

1 Department of Natural Resources and Environmental Studies, National Dong Hwa University, Hualien, Taiwan

2 Department of Biological Sciences, Simon Fraser University, British Columbia, Canada

3 Institute of Marine Biology, National Dong Hwa University, Pingtung, Taiwan

4 National Museum of Marine Biology and Aquarium, Pingtung, Taiwan maximum quantum yield (Fv/Fm), a measurement of symbiont photochemical performance. We found no direct evidence that thermal conditioning of adult $P$. acuta corals improves offspring performance in warmer water; however, chronic exposure of parent colonies to warmer temperatures at the source reef site may have limited transgenerational acclimation capacity. The extent to which coral response to this active management approach might vary across species and sites remains unclear and merits further investigation.

Keywords Thermal pre-conditioning - Acclimation . Resilience $\cdot$ Climate change $\cdot$ Taiwan

\section{Introduction}

Coral reefs have declined dramatically over the past several decades (Bellwood et al. 2004; Bruno and Selig 2007; Hughes et al. 2017a). This is of concern because coral reefs harbour high biodiversity (Côté and Knowlton 2013) and provide critical ecosystem services to millions of people globally (Woodhead et al. 2019). The many drivers of coral decline include a range of natural (e.g. disease, storms) and human-induced (e.g. pollution, fishing) local stressors (Nyström et al. 2000; Burke et al. 2011). But it is chronic ocean warming and acute thermal anomalies induced by climate change that pose the greatest threat to the persistence of corals (Hoegh-Guldberg et al. 2007, 2017; Carpenter et al. 2008; Hughes et al. 2017b).

Corals are sensitive to warming; even small increases in ocean temperature can result in substantial physiological changes in these habitat-forming species. For example, increased water temperature can alter reproductive timing (Crowder et al. 2014; Fan et al. 2017), fertilization/ 
embryogenesis (Negri et al. 2007; Albright and Mason 2013), larval physiology (Putnam et al. 2010; Edmunds et al. 2011), pelagic dispersal (Heyward and Negri 2010; Figueiredo et al. 2014), growth (Edmunds 2008; Cantin et al. 2010) and survival of corals (Randall and Szmant 2009; McManus et al. 2019). Mean global sea surface temperature has already risen by $1{ }^{\circ} \mathrm{C}$ since pre-industrial levels, mostly in the past 50 years and additional warming of $\sim 1-4{ }^{\circ} \mathrm{C}$ is expected by 2100 (IPCC 2019). A temperature increase of this nature will surpass the physiological thermal limits of many coral species, leading to coral bleaching and mortality (Hoegh-Guldberg 1999; Frieler et al. 2013). Mass coral bleaching events, which have occurred episodically at a global scale since 1998 (Wilkinson 1998), are now occurring with increased frequency and magnitude (Hughes et al. 2018; Eakin et al. 2019; IPCC 2019).

The extent to which climate change-induced warming will affect corals in the short term rests primarily on the corals' capacity to withstand, and potentially adapt to, warming conditions. Coral thermal tolerance is highly variable (Fitt et al. 2001). There are a wide range of temperature thresholds observed across species and reef sites (Loya et al. 2001; Oliver et al. 2011; van Woesik et al. 2011), and the mechanisms and duration of these tolerances are diverse and dynamic (Brown et al. 2014; CarballoBolaños et al. 2020). For example, corals from warmer (Howells et al. 2016a, b) or thermally variable reefs (Safaie et al. 2018) and species possessing specific traits (e.g. thick tissues; Putnam et al. 2017) or a high capacity for heterotrophic feeding (Grottoli et al. 2006) can show higher resistance and/or resilience to higher temperatures. Tolerance, however, is not static; coral species that were 'winners' in the past can become 'losers' during subsequent heat stress events (Grottoli et al. 2014) and corals thought to be thermally sensitive can acclimate relatively quickly (within $\sim 2$ years) when translocated to a thermally variable reef (Palumbi et al. 2014). This fluidity in thermal tolerance provides a glimmer of hope for corals: a high plasticity that might lead to acclimation or adaptation to a warming ocean. By better understanding the mechanisms underlying plasticity in thermal tolerance, scientists and managers may be able to harness this capacity and actively enhance coral resistance and resilience.

One proposed management approach focused on coral thermal tolerance is assisted evolution (van Oppen et al. 2015). Since the current rate of ocean warming is greater than what corals have experienced in the past (Pandolfi et al. 2011), there is concern that corals will not be able to adapt quickly enough to match the pace of environmental change (Hoegh-Guldberg et al. 2007; Matz et al. 2018; van Oppen et al. 2017). Assisted evolution aims to give corals a 'helping hand' by speeding up natural acclimation and adaptation processes, thereby actively increasing coral resistance and resilience to ocean warming (van Oppen et al. 2015). One potential means of accomplishing this is through thermal preconditioning of adult coral colonies to trigger an epigenetic response that could increase the thermal tolerance of their offspring-a process variably referred to as transgenerational acclimation (van Oppen et al. 2015), transgenerational transfer (Ho and Burggren 2010), transgenerational plasticity (Torda et al. 2017; Donelson et al. 2018), or cross- and multigenerational plasticity (Bryne et al. 2020). Although a wide range of organisms have been the focus of transgenerational acclimation studies (Ho and Burggren 2010; Bryne et al. 2020), corals remain relatively understudied. Putnam and Gates (2015) first showed that preconditioning of adult coral colonies to increased temperature and $\mathrm{pCO}_{2}$ could lead to metabolic acclimation in offspring. Subsequently, there have been few studies that explore the potential of this new technique as a means of mitigating coral decline in the face of climate change (but see Bellworthy et al. 2019; Putnam et al. 2020). Likely explanations for the paucity of transgenerational acclimation studies on corals include the temporal, logistical and financial challenges of assessing multi-generational effects on relatively long-lived species. Simplifying the process of transgenerational acclimation might therefore provide a useful tool both to assess the extent of benefits to corals and to implement it for management purposes.

Here, we used a relatively simple, low-tech approach to assess the outcomes of transgenerational acclimation, which considers ecological rather than molecular or genetic metrics of 'success'. Specifically, we asked whether thermal preconditioning of adult colonies of the reef-building coral Pocillopora acuta provides a benefit to offspring when the latter are subsequently exposed to high temperature. $P$. acuta is a hermaphroditic species with a mixed, yet predominately brooding, reproductive strategy, with larvae produced both asexually and sexually (Yeoh and Dai 2010; Smith et al. 2019). We examined the influence of adult conditioning across three critical coral life-history stages: reproduction, recruitment and recruit performance, and assessed ecological metrics that are easily measured such as larval abundance, survival, size and symbiont photochemical performance.

\section{Materials and methods}

\section{Study site and coral collection}

We collected 24 colonies of $P$. acuta (diameter, mean \pm SD: $13.56 \pm 2.2 \mathrm{~cm}$ ) (Kenting National Park collection permit \#: 1,050,002,277) in February 2017 from depths of 
3-5 $\mathrm{m}$ at Outlet Reef, a fringing reef in Nanwan Bay, southern Taiwan (Fig. S1). Outlet Reef is situated near Taiwan's 3rd nuclear power plant and, consequently, experiences summer temperatures that are typically $\sim 2-3{ }^{\circ} \mathrm{C}$ warmer than the surrounding reefs in the region (Keshavmurthy et al. 2012). Despite widespread bleaching after the construction and initial operation of the nuclear plant in the late 1980s (Hung et al. 1998), corals in the area have recovered, albeit with a change in community composition (Keshavmurthy et al. 2014). In addition to the warming influence of the nuclear plant effluent, Outlet Reef can experience substantial fluctuations in daily temperature (typically $\pm 2-3{ }^{\circ} \mathrm{C}$, but a drop of up to $10{ }^{\circ} \mathrm{C}$ has been recorded) due to internal tide-induced upwelling in Nanwan Bay (Lee et al. 1997; Jan et al. 2004).

Collected coral colonies were immediately transported to the research center at the nearby National Museum of Marine Biology and Aquarium (NMMBA) and held in a recovery tank for 7 days where they were monitored for signs of bleaching and disease. Colonies were held in a semi-enclosed outdoor area exposed to ambient light, partly shaded to approximate conditions at the collection site; water temperature $\left(25.1{ }^{\circ} \mathrm{C} \pm 0.7\right)$ was similar to that experienced at Outlet reef $\left(25.4{ }^{\circ} \mathrm{C} \pm 0.5\right.$ in February 2017). Seawater in the flow-through recovery system was sand-filtered and sourced offshore from NMMBA.

\section{Experimental system and parental treatments}

Coral colonies were moved into individual 14-L tanks, in an indoor flow-through experimental system (flow rate: $\sim 7 \mathrm{ml} \mathrm{s}^{-1}$ ) (Fig. 1b). Tanks were lit with LED lights (ComboRay G2; Illumagic, Taiwan), with a light intensity of $\sim 200 \mu \mathrm{mol}$ photons $\mathrm{m}^{-2} \mathrm{~s}^{-1}$ (measured using a LI-COR PAR sensor; LICOR Biosciences, USA) on a $12 \mathrm{~h}: 12 \mathrm{~h}$ light/dark photoperiod with light exposure from 06:00-18:00, which was similar to natural daylight hours. Sand-filtered seawater ran through an additional 3 -tier filtration unit $(100,75,50 \mu \mathrm{m})$ before entering the experimental system. Air temperature was maintained at $26{ }^{\circ} \mathrm{C}$ throughout the experiment. Colonies were fed a commercial feed (Coral Frenzy) three times a week.

We randomly assigned colonies to either a control group $\left(26.2{ }^{\circ} \mathrm{C} \pm 0.4 ; \mathrm{n}=12\right)$ or a heated group $\left(29.7{ }^{\circ} \mathrm{C} \pm 0.3\right.$; $\mathrm{n}=12$; Fig. 1a). The control temperature was representative of the spring temperature at Outlet reef (March-May 2017, mean \pm SD: $26.7^{\circ} \mathrm{C} \pm 1.2$ ), and the heated temperature was purposely set at a temperature above any experienced in spring but slightly below summer mean temperature at Outlet reef (July_August 2017, mean \pm SD: $30.1 \pm 1.1$ ) (Fig. S6). Heated tank temperature was controlled in each tank with a $150 \mathrm{~W}$ heater; temperature was increased from $26{ }^{\circ} \mathrm{C}$ to $29.5{ }^{\circ} \mathrm{C}$ (rate: $+0.5{ }^{\circ} \mathrm{C}$ /
$12 \mathrm{~h}$ ) over the course of 3 days. We measured colony maximum quantum yield $(\mathrm{Fv} / \mathrm{Fm})$, which estimates quantum efficiency of photosystem II, i.e. a measurement of symbiont photochemical performance (Iglesias-Prieto et al. 1992; Jones et al. 2000), every two weeks with a diving PAM (Heinz Walz GmbH, Germany; settings: saturation pulse intensity $=8$, measurement light intensity $=8$, gain $=2$, damp $=2$ ). Prior to $\mathrm{Fv} / \mathrm{Fm}$ measurements, colonies were dark adapted for $30 \mathrm{~min}$ and 3 replicate measurements were taken on each colony. Temperature was recorded every 10 min with $\mathrm{HOBO}$ pendant temperature loggers; each colony tank had its own logger (UA-002-08, Onset Computer Corporation, USA) (Fig. S2).

\section{Reproduction and planulae measurements}

The outflow pipe of each colony tank was fitted with a $100 \mu \mathrm{m}$-mesh cup to facilitate the collection of coral larvae (hereafter referred to as planulae). We counted the planulae released from each colony daily at $\sim$ 09:00 for three reproductive cycles (March, April and May 2017). Any planula that had settled on the tank or was swimming in the tank (i.e. had not passed into the collection cup) was counted and included in the daily total enumeration for each colony; tanks were scrubbed each day post-counts to ensure accuracy across days. The majority $(>80 \%)$ of planulae, however, were collected via the collection cup. We measured planula length and $\mathrm{Fv} / \mathrm{Fm}$ daily during the four treatment-specific peak days of release for each reproductive cycle; we focussed solely on peak release days because planulae size, respiration rates and susceptibility to stressors are known to differ across the larval release period (Cumbo et al. 2012, 2013). More than twothirds $(71.8 \% \pm 12.9 \%)$ of all planulae produced were released each month on these peak days (Table S1). Planula length ( $n=10$ planulae/colony) was measured under a dissecting microscope. We measured only larvae that were elongate and swimming to standardise developmental stage. Fv/Fm was assessed using a diving PAM (settings: saturation pulse intensity $=11$, measurement light intensity $=11$, gain $=8$, damp $=2$ ). Planulae were pooled across colonies based on parent temperature, separately for each of the four peak release days and dark adapted for $30 \mathrm{~min}$. Ten independent $\mathrm{Fv} / \mathrm{Fm}$ measurements, each containing $\sim 15$ planulae, were then taken for each temperature treatment group on each of the four days of peak larval release. To do this, we attached a small flexible plastic pipe extension ( $\sim 1 \mathrm{~cm}$ in length) to the end of the diving PAM cable, held the cable upright and placed planulae within this pipe extension for each independent measurement. We did not assess whether planulae were the product of sexual or asexual reproduction. 

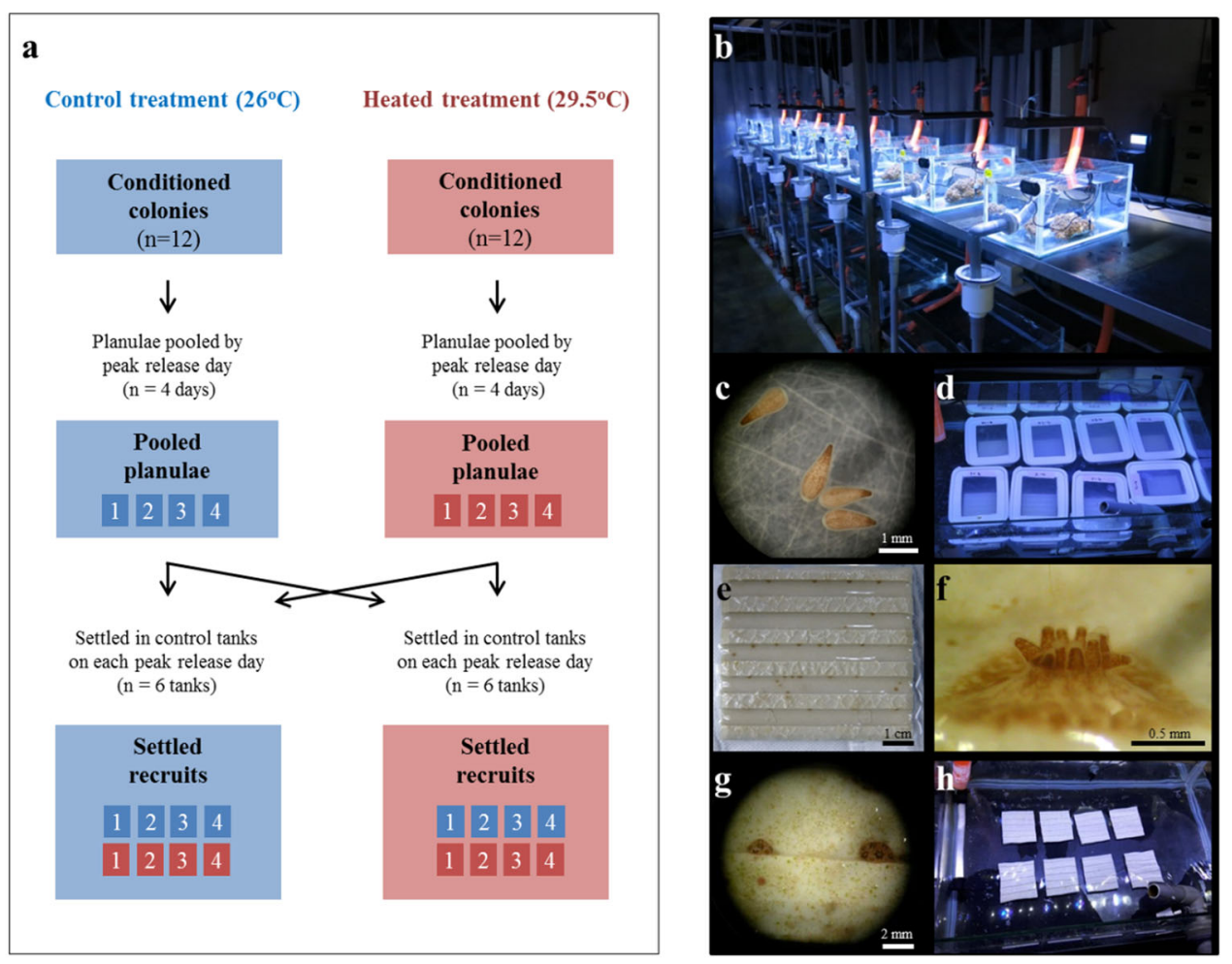

Fig. 1 Overview of experimental design. Reproductive timing and planulae production of colonies in control $\left(26^{\circ} \mathrm{C}\right)$ and heated $\left(29.5^{\circ} \mathrm{C}\right)$ treatments were monitored daily across three reproductive cycles (March to May 2017). Planulae size and maximum quantum yield (Fv/Fm) were measured independently across the 4 peak days of reproduction each month. In April and May, planulae were pooled based on parent temperature separately for each of the 4 peak days of

\section{Recruitment, survival and growth}

To examine the recruitment, survival and growth of coral recruits, we again pooled planulae based on parent temperature (treatment pools comprised approximately the same number of planulae from each colony), separately for each of the four peak release days of the April and (separately) May reproductive cycles. For each peak day, pooled planulae from each parent treatment were divided evenly across 12 recruitment containers (with $n=30$ and $n=40$ planulae/container for April and May, respectively, across a total of 24 containers). For each parent treatment container set, six of the containers were assigned randomly to one of six $26{ }^{\circ} \mathrm{C}$ recruitment tanks $(60 \mathrm{~L})$ and the remaining six containers were assigned to one of the six $29.5{ }^{\circ} \mathrm{C}$ recruitment tanks. Thus, each recruitment tank held one planula container from each parent temperaturepeak release day combination (i.e. 8 containers; see Fig. 1a for experimental design overview). The same recruitment container arrangement was used for both April and May recruitment; each recruitment month used independent recruitment tanks ( $n=12$ recruitment tanks/month). reproduction and settled at either $26^{\circ} \mathrm{C}$ or $29.5^{\circ} \mathrm{C}$ where they grew as recruits. a schematic of experimental design; $\mathbf{b}$ colonies within a flow-through system for the collection of planulae; $\mathbf{c}$ newly released planulae; d recruitment containers used for the first week of planula recruitment; e newly settled recruits on a conditioned tile; f recruit $\sim 1$-week post-recruitment; g recruits $\sim 3$-weeks post-recruitment; $\mathbf{h}$ tiles with recruits held within a recruitment tank

In each container $\left(\right.$ volume $\left.=540 \mathrm{~cm}^{3}\right)$, we placed one ceramic tile $(7 \times 7 \mathrm{~cm})$ that had been pre-conditioned for 1 month in a tank rich in crustose coralline algae to facilitate coral recruitment (i.e. planulae attachment to the tile). The plastic containers had meshed $(100 \mu \mathrm{m})$ sides and lid to facilitate water flow (see Fig. 1d). Recruitment on each tile was recorded daily for one week, after which the tiles were removed from the recruitment containers and placed directly within the recruitment tanks. Recruit survival, growth and $\mathrm{Fv} / \mathrm{Fm}$ were then monitored $1,3,7$ and 9 weeks post-recruitment. A recruit was considered dead if it had bleached completely and no polyp was visible under the microscope. Growth was assessed based on changes in recruit diameter, measured under a dissecting microscope (magnification $=10 x$ ), over the course of the experiment. Recruit position was mapped on each tile, and each recruit was assigned an individual number to ensure identification over time. Recruits that settled on the edge of the tile were not included in our analyses because it was not possible to measure their size accurately; this was the case for $\sim 5 \%$ of settled recruits. Fv/Fm of individual recruits was measured using a diving PAM (settings: saturation pulse 
intensity $=11$, measurement light intensity $=11$, gain $=8$, damp = 2) after careful removal of any surrounding algae; recruits were dark adapted for $30 \mathrm{~min}$ prior to measurement. Recruits were fed a commercial feed (Coral Frenzy) three times a week.

\section{Statistical analyses}

We used Rayleigh tests to assess the daily distribution of planulae release for each of the three reproductive cycles. Watson's tests were used to investigate differences in reproductive timing between treatments each month. We used generalized linear models to assess (1) the effects of parent temperature treatment and colony size on the number of planulae released for each reproductive cycle (with a Poisson distribution) and (2) the effect of parent temperature on planulae Fv/Fm. We used linear mixedeffects models to assess (1) the effect of treatment temperature over time on colony $\mathrm{Fv} / \mathrm{Fm}$ (with colony as a random effect), (2) the effect of parent treatment temperature on planulae size each month (with colony as a random effect) and (3) the effect of parent temperature and recruitment temperature (and their interaction) over time on recruitment, growth and Fv/Fm of recruits (with tile [ $n=96 /$ month $]$ nested within recruitment tank $[n=12$ tanks/month] as random effects; recruitment analyses only used tank as a random effect). Recruit survival was assessed using Cox mixed-effects models with tile nested within recruitment tank as random effects. All analyses were done in $\mathrm{R}$ ( $\mathrm{R}$ Core Team 2019) using the packages circular (Agostinelli and Lund 2017), car (Fox and Weisberg 2019), lme4 (Bates et al. 2015), lmerTest (Kuznetsova et al. 2017), MuMIn (Barton 2009), survival (Therneau 2015), survminer (Kassambara et al. 2019) and coxme (Therneau 2020).

\section{Results}

\section{Colony reproductive timing and planula abundance}

The cumulative duration of exposure of coral parent colonies to temperature treatments at the onset of each reproductive cycle was approximately 5 days (Month 1; March), 30 days (Month 2: April) and 60 days (Month 3: May). There was a unimodal distribution of planula release within both temperature treatments for all months (Rayleigh tests, $p<0.001$ ) (Table 1; Fig. S3). There was no difference in reproductive timing between temperature treatments in March; however, in April and May, colonies held at $29.5{ }^{\circ} \mathrm{C}$ released planulae significantly earlier in the lunar cycle (Watson's tests, April: $\mathrm{F}=0.63, \mathrm{p}<0.001$; May: $\mathrm{F}=0.94, p<0.001$ ) (Fig. 2a, Table 1). For colonies held at $26{ }^{\circ} \mathrm{C}$ (control), there was no difference in reproductive timing between March and May, but planulae were released earlier in the lunar cycle in April (compared to March and May) (Table S2). For colonies held at $29.5^{\circ} \mathrm{C}$, planulae were released earlier in the lunar cycle in April and May (compared to March), but there was no difference in timing between April and May (Table S2).

Colonies in the heated treatment released fewer planulae than control colonies in March and April (mean $\pm \mathrm{SE}$, March: control $571 \pm 103$, heated: $516 \pm 79$, April: control $1160 \pm 173$, heated: $671 \pm 173$; generalized linear model, March: $\mathrm{z}=-6.59, p<0.001$; April: $\mathrm{z}=-36.85$, $p<0.001$ ), but produced more in May (mean \pm SE, May: control $693 \pm 223$, heated: $908 \pm 278$; generalized linear model, $\mathrm{z}=12.24, p<0.001$ ) (Fig. 2b; Table S3). Greater reproduction in May appears to be due to one colony in the heated treatment that produced $\sim 3400$ planulae, much higher than the average for other colonies in the same treatment. When this outlier colony was removed from the May analysis, colonies in the control treatment produced more planulae (mean $\pm \mathrm{SE}$, control $756 \pm 225$, heated: $678 \pm 172$; generalized linear model, $\mathrm{z}=-6.90$, $p<0.001$; Table S3). Colony size had a significant effect on the number of planulae released across all months, whereby larger colonies produced more planulae (generalized linear models, March: $\mathrm{z}=21.13, p<0.001$; April: $\mathrm{z}=30.75, p<0.001$; May: $\mathrm{z}=6.26, p<0.001$; May with outlier removed: $z=2.30, p=0.003$ ) (Fig. S4; Table S3). There was no difference in colony diameter between treatments $\left(\right.$ mean $\pm \mathrm{SE} ; 26^{\circ} \mathrm{C}: 13.50 \mathrm{~cm} \pm 0.59 \mathrm{~cm}$, $29.5^{\circ} \mathrm{C}$ : $\quad 13.62 \mathrm{~cm} \pm 0.65 \mathrm{~cm}$; Mann-Whitney test, $\mathrm{W}=82.5, p=0.56)$. Colonies in the heated treatment had lower Fv/Fm (linear mixed-effects model, $\mathrm{t}=-3.07$, $p=0.006)$ and Fv/Fm decreased over time in both treatments (linear mixed-effects model, $\mathrm{t}=-9.37, p<0.001$ ) (Fig. 2c; Table S4).

\section{Planula size, Fv/Fm and recruitment}

In March, there was no difference in the size of planulae released by adult corals held at either temperature (linear mixed-effects model $p>0.05$; Table S5). However, in both April and May, planulae released by adults held at $29.5{ }^{\circ} \mathrm{C}$ were significantly smaller than those released from colonies at $26{ }^{\circ} \mathrm{C}$ (linear mixed-effects models, April: $\mathrm{t}=-2.77, \quad p=0.013 ;$ May: $\mathrm{t}=-5.71, \quad p<0.001)$ (Fig. 3a; Table S5). The incorporation of colony as a random effect in the planulae size models increased the $\mathrm{R}^{2}$ value by 0.16 (March), 0.12 (April) and 0.11(May), indicating a parental colony effect. There was no difference in Fv/Fm between planulae released by adults under different temperature treatments (generalized linear models, April: $p>0.05$; May: $p>0.05$; Fig. 3b; Table S6). After 6 days 
Table 1 Timing of planula release by Pocillopora acuta from March to May 2017, converted to mean angle in circular distributions (see Fig. S3) and results of Rayleigh tests for uniformity of distribution and Watson's tests for homogeneity of reproductive timing by coral colonies held at either $26{ }^{\circ} \mathrm{C}$ or $29.5^{\circ} \mathrm{C}$. Sample size is 11 for the control treatment in April and May due to the death of one colony. Lunar day 1 refers to the new moon

\begin{tabular}{|c|c|c|c|c|c|c|c|}
\hline Treatment & $\mathrm{N}$ & Mean angle & Mean lunar day & Rayleigh test $\mathrm{r}$ & $P$-value & Watson's test F & $P$-value \\
\hline \multicolumn{8}{|l|}{ March } \\
\hline $26^{\circ} \mathrm{C}$ & 12 & 116 & 9.34 & 0.84 & $<0.001$ & \multirow[t]{2}{*}{0.18} & \multirow[t]{2}{*}{$>0.05$} \\
\hline $29.5^{\circ} \mathrm{C}$ & 12 & 89 & 7.17 & 0.87 & $<0.001$ & & \\
\hline \multicolumn{8}{|l|}{ April } \\
\hline $26^{\circ} \mathrm{C}$ & 11 & 90 & 7.25 & 0.74 & $<0.001$ & \multirow[t]{2}{*}{0.63} & \multirow[t]{2}{*}{$<0.001$} \\
\hline $29.5^{\circ} \mathrm{C}$ & 12 & 48 & 3.87 & 0.88 & $<0.001$ & & \\
\hline \multicolumn{8}{|l|}{ May } \\
\hline $26^{\circ} \mathrm{C}$ & 11 & 98 & 7.89 & 0.82 & $<0.001$ & \multirow[t]{2}{*}{0.94} & \multirow[t]{2}{*}{$<0.001$} \\
\hline $29.5^{\circ} \mathrm{C}$ & 12 & 44 & 3.54 & 0.82 & $<0.001$ & & \\
\hline
\end{tabular}

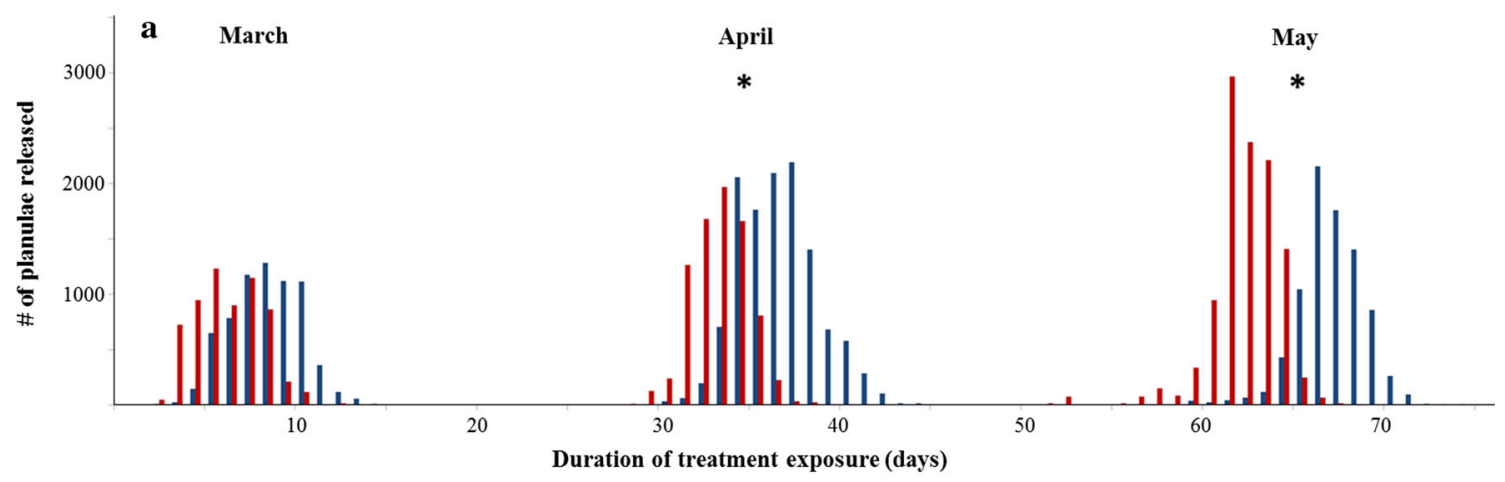

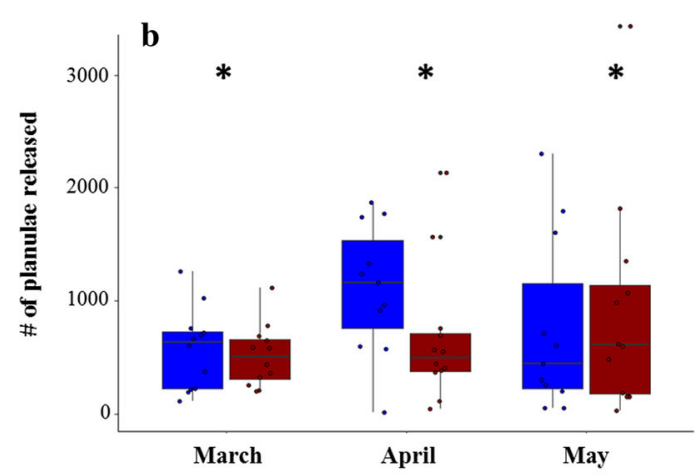

Fig. 2 Response of adult Pocillopora acuta coral colonies held within control $\left(26^{\circ} \mathrm{C}\right.$; blue) and heated $\left(29.5^{\circ} \mathrm{C}\right.$; red) treatments across three reproductive cycles (March to May 2017). a Total number of planulae released in each month across all colonies in each treatment for each day of the experiment; $\mathbf{b}$ mean number of planulae released per colony each month; c colony maximum quantum yield

post-release, the proportion of planulae that settled did not differ based on parent treatment temperature (for either recruitment month), but was lower in the heated recruitment tanks in April (linear mixed-effects models, $\mathrm{t}=-2.35, p=0.026)($ Fig. S5, Table S7).

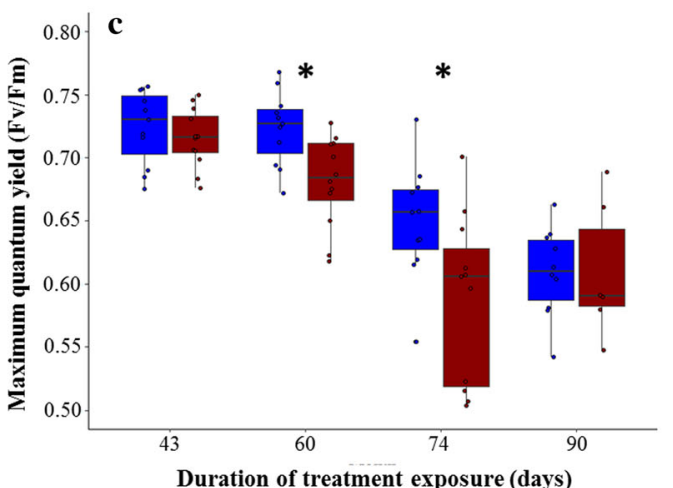

(Fv/Fm). No data are available for March due to equipment malfunction. The line in the boxplots shows the median value, and the bottom and top of the box represent the 25th and 75th quartile ranges, respectively. Asterisks indicate significant differences between parental temperature treatments

\section{Recruit survival, size and Fv/Fm}

Recruit survival did not differ based on parent or recruitment temperature in April. In May, however, survival of recruits sourced from adults held at $29.5{ }^{\circ} \mathrm{C}$ was lower when they settled at $29.5^{\circ} \mathrm{C}$ than when they settled at the 


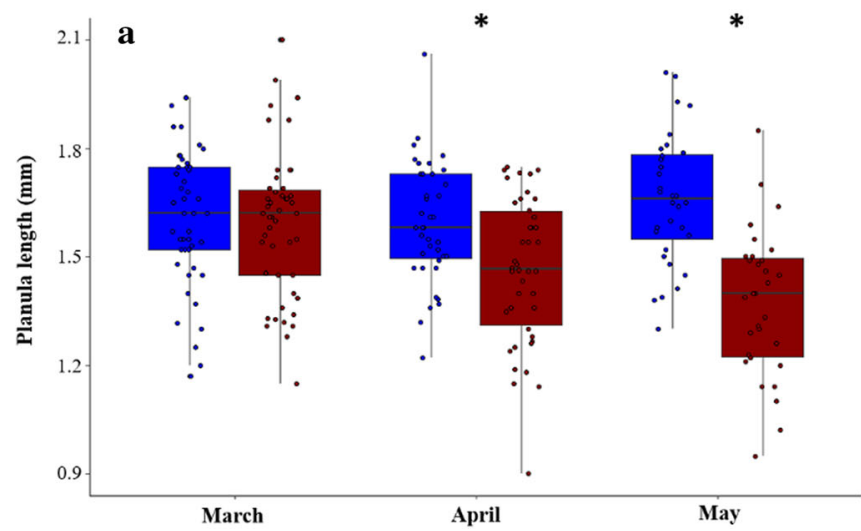

Fig. 3 Response of Pocillopora acuta planulae released from colonies held within control $\left(26^{\circ} \mathrm{C}\right.$; blue $)$ and heated $\left(29.5^{\circ} \mathrm{C}\right.$; red) treatments across three reproductive cycles (March to May 2017). a Mean length of planulae. Asterisks indicate significant differences between parental temperature treatments; b Mean maximum quantum

control temperature (Cox mixed-effects model, $\mathrm{z}=2.86$, $p=0.004$ ) (Fig. 4a; Table S8). No difference in survival based on recruitment temperature was observed for recruits sourced from adults held at $26^{\circ} \mathrm{C}$. Recruits sourced from parent colonies in the $29.5^{\circ} \mathrm{C}$ treatment were significantly smaller (linear mixed-effects models, April: $\mathrm{t}=-5.08$, $p<0.001 ; \quad$ May: $\mathrm{t}=-14.14, \quad p<0.001$ ) (Fig. 4b; Table S9) and had lower Fv/Fm (linear mixed-effects models, April: $\mathrm{t}=-4.23, p<0.001$; May: $\mathrm{t}=-3.65$, $p=0.002$ ) (Fig. 4c; Table S10) than recruits sourced from adults in the control treatment. Recruitment temperature did not affect recruit size or $\mathrm{Fv} / \mathrm{Fm}$ in either recruitment month (linear mixed-effects models, $p>0.05$ ) (Tables $\mathrm{S} 9$ $\&$ S10). The interaction between parent and recruitment temperature was significant in May for recruit size (linear mixed-effects model, $\mathrm{t}=2.83, p<0.001$ ), with recruits sourced from heated adults being larger when grown at $29.5^{\circ} \mathrm{C}$, than at $26^{\circ} \mathrm{C}$, while the reverse was observed for recruits sourced from adults held at ambient temperature (Fig. 4b). In both months, recruit size increased over time (April: $\mathrm{t}=35.22, p<0.001$; May: $\mathrm{t}=16.01, p=0.006$ ) and Fv/Fm decreased (April: $\mathrm{t}=-19.97, p<0.001$; May: $\mathrm{t}=-9.98, p<0.001)($ Tables S9 \& S10).

\section{Discussion}

To evaluate the potential capacity for transgenerational acclimation in corals, we examined the physiological and demographic responses to temperature of adult $P$. acuta colonies, planulae and recruits. Thermal conditioning at $29.5{ }^{\circ} \mathrm{C}$ led to earlier reproduction, reduced reproductive investment and lower symbiont photochemical performance associated with adult colonies. Planulae released from thermally conditioned adults were smaller than those

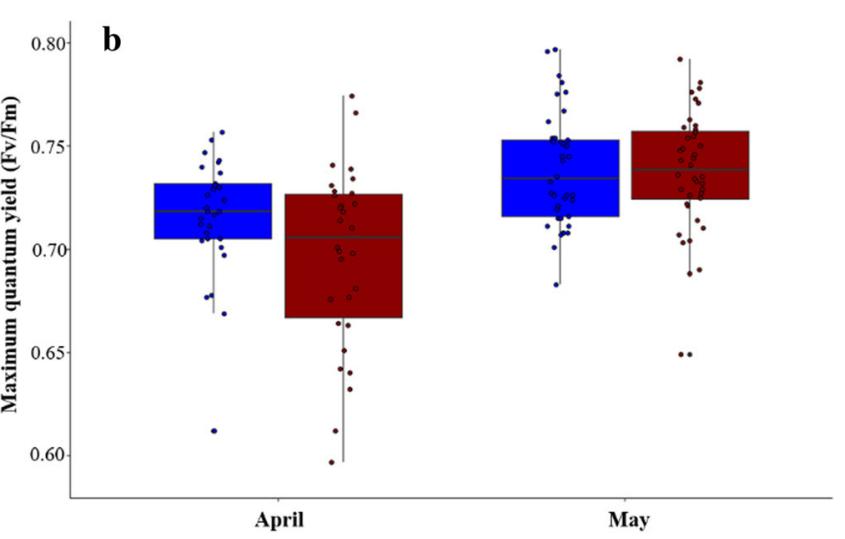

yield of planulae (Fv/Fm); no data are available for March due to equipment malfunction. The line in the boxplots shows the median value, and the bottom and top of the box represent the 25th and 75th quartile ranges, respectively

from control $\left(26^{\circ} \mathrm{C}\right)$ parents, but $\mathrm{Fv} / \mathrm{Fm}$ was similar. Recruitment did not differ based on parent treatment but was lower at the heated recruitment temperature in the second month of the experiment. Recruit survival was not significantly affected by either parent or recruitment temperature. However, recruits sourced from thermally conditioned parents were smaller and had lower Fv/Fm by the end of the experiment. Taken together, our results do not support the notion that thermal conditioning of $P$. acuta adult colonies sourced from a chronically warmed reef benefits offspring when they settle and grow in warm conditions.

\section{Reproductive timing, planulae investment and recruitment}

Coral colonies held in warmer water reproduced earlier. On average, larval release by heated colonies was 3.4 days (April) and 4.4 days (May) earlier than by control colonies. Shifts to earlier reproduction in response to warming have been observed in brooding and spawning corals, both experimentally (Crowder et al. 2014; Paxton et al. 2016) and in the wild (Nozawa 2007; Fan et al. 2017). Typically, reproductive timing is controlled by specific environmental cues (e.g. lunar irradiance, daylight cycles, sea surface temperature, wind fields), which can vary across species and regions (Fan et al. 2006; Brady et al. 2009; van Woesik 2010; Harrison et al. 2011; Lin and Nozawa 2017). In some cases, changes in reproductive timing can be a response to an acute stress event (e.g. high nutrient conditions; Cox and Ward 2002; temperature perturbations from upwelling; Tew et al. 2014). Climate change-induced warming, however, is chronic stressor, and a more permanent shift to earlier reproduction could lead to incomplete (or faster) gametogenesis and/or a mismatch between the timing of 
$\mathbf{a}$
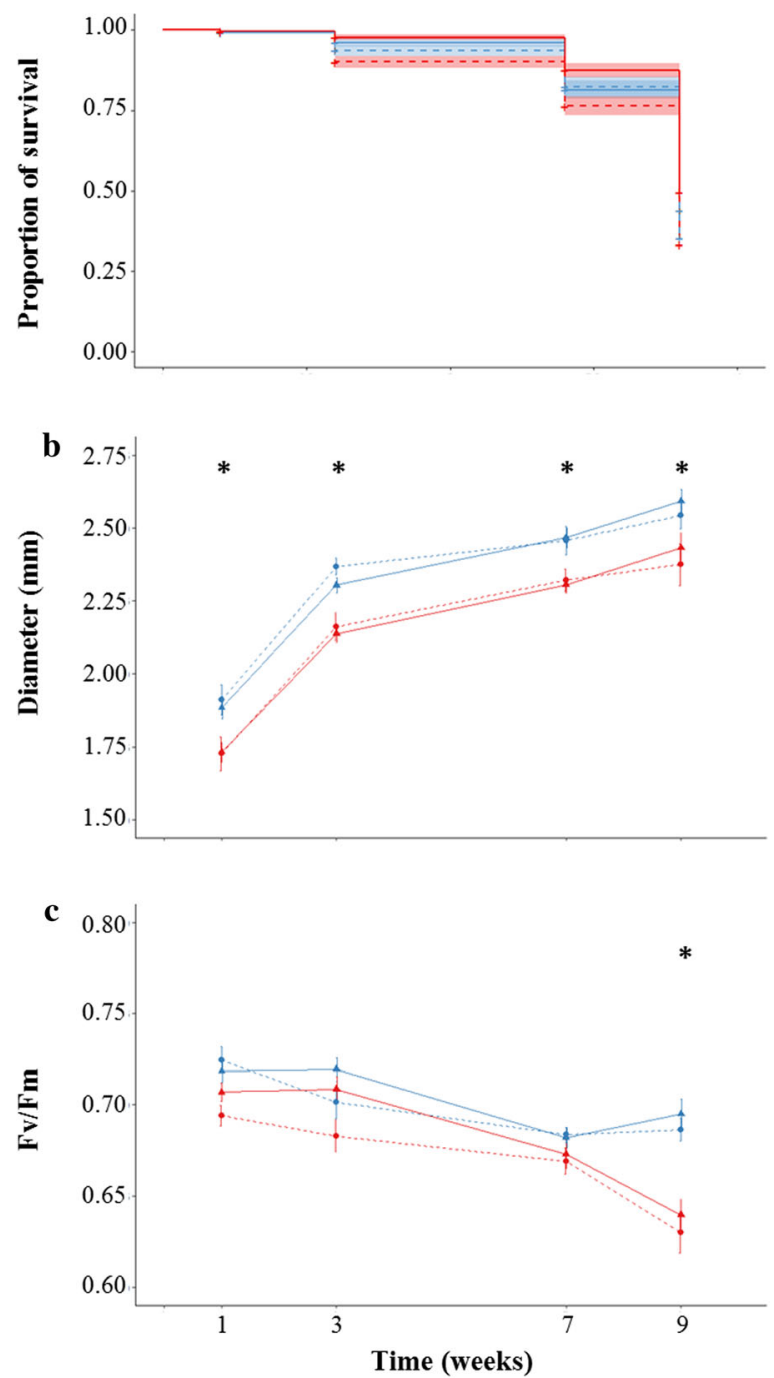

Fig. 4 a Survival, b size and c Fv/Fm of Pocillopora acuta coral recruits produced by parent colonies held in control $\left(26^{\circ} \mathrm{C}\right.$; blue lines) or heated $\left(29.5{ }^{\circ} \mathrm{C}\right.$; red lines) water and then grown in control $\left(26{ }^{\circ} \mathrm{C}\right.$; solid lines) and heated $\left(29.5{ }^{\circ} \mathrm{C}\right.$; dashed lines) recruitment tanks. Recruits sourced from the April and May planulation periods

planula release and of optimal conditions for larval survival (Shlesinger and Loya 2019).

Thermally conditioned colonies produced fewer offspring than colonies held at $26^{\circ} \mathrm{C}$. Decreased fecundity under thermal stress has been found across a wide range of coral species (McClanahan et al. 2009; Paxton et al. 2016; Howells et al. 2016a, b) and is underpinned at a physiological level by increased metabolism and depleted adult lipid reserves (Grottoli et al. 2004; Rodrigues et al. 2008). Indeed, symbiont photochemical performance (Fv/Fm) decreased over the course of the experiment and significantly more so in colonies held in the heated treatment. Similar decreases in colony $\mathrm{Fv} / \mathrm{Fm}$ in other
May
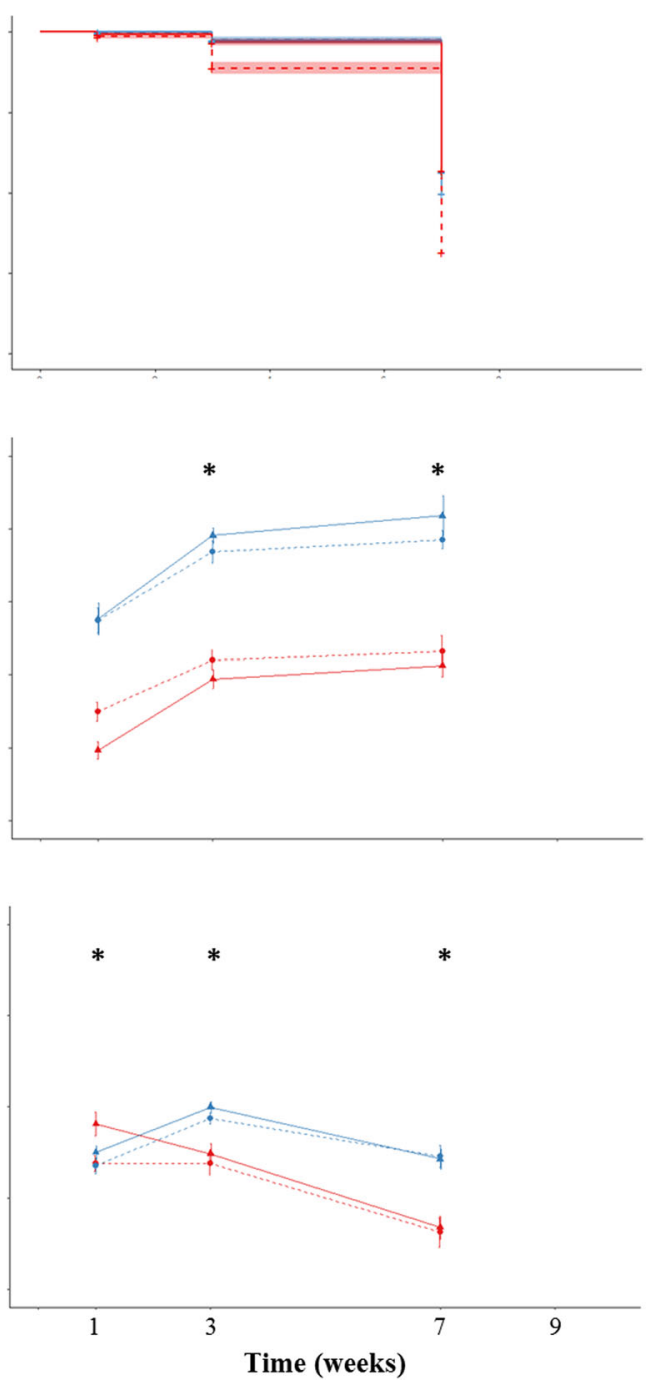

were held in independent recruitment tanks ( $n=12$ tanks/month). Data for week 9 in May were not included due to small sample size. Asterisks indicate significant parent treatment effect; there were no significant recruitment temperature effects (see Tables S9, S10, S12$15)$

transgenerational acclimation experiments, both between treatments (Putnam and Gates 2015) and over time (Bellworthy et al. 2019), underscore the limitations of thermal conditioning of adult colonies: long-term reproduction in a laboratory setting is finite due to declines in adult health (but see Craggs et al. 2020).

Planulae released by thermally conditioned adults were smaller than those produced by corals under control temperatures. This smaller size (see also Putnam and Gates 2015), coupled with the reduced fecundity of heated adults, points to significantly reduced reproductive investment by corals exposed to high temperature. It is not clear whether small size would be an advantage or a detriment to coral 
larvae. On one hand, the high size-specific metabolic rate of small coral planulae brooded by parents exposed to high temperature could hasten recruitment and post-recruitment growth (Putnam and Gates 2015). On the other hand, smaller larvae can contain a smaller amount of lipids than larger larvae (e.g. de Putron et al. 2017) and the rapid use of these limited lipid reserves at increased temperatures (Rivest and Hofmann 2015) could limit the time window for pelagic dispersal, larval ability to find suitable habitat and ultimately recruitment success (Richmond 1987; Isomura and Nishihira 2001). Moreover, small larvae may turn into small recruits and recruit survival has been related to size (e.g. Raymundo and Maypa 2004). There was no difference in $\mathrm{Fv} / \mathrm{Fm}$ in planulae sourced from control or heated parents (see also Putnam et al. 2008; Bellworthy et al. 2019 for similar Fv/Fm of planulae at different temperatures). The similarity of planula $\mathrm{Fv} / \mathrm{Fm}$ in our experiment suggests that the photosynthetic capacity between treatments is likely equivalent. However, it is important to note that size does not necessarily have a significant effect on the density of Symbiodiniaceae within planulae (Isomura and Nishihira 2001; P. damicornis) and that Symbiodiniaceae do not play a large role in the provision of energy to pelagic planulae (Kopp et al. 2016).

Final recruitment (i.e. the total number of recruits settled on a tile after 6 days) was lower at higher temperature, regardless of parental temperature in the April recruitment and unaffected by temperature in the May recruitment. Increased temperature can have a variable influence on recruitment, with evidence of no effect of parental (Bellworthy et al. 2019) or recruitment temperature (Anlauf et al. 2011; Chua et al. 2013), or increased mortality following initially high recruitment (Nozawa and Harrison 2007). The lack of a consistent recruitment disadvantage across the two recruitment months and the absence of a parent temperature effect suggest that the treatment temperatures used in this study were within an acceptable range for recruitment for corals sourced from Outlet reef (see Fig. S6).

\section{Offspring response to parental thermal conditioning: recruit survival, growth and symbiont photochemical efficiency}

Neither parent nor recruitment temperature affected recruit survival, but recruit size and symbiont photochemical performance were affected by parental temperature. Mortality of recruits in both temperature treatments generally increased over time, especially in the May recruitment, but this is typical of this early recruit life stage (Sato 1985). In May, survival of recruits sourced from heated adults was lower at the heated temperature than at the control recruitment temperature - a pattern not observed for recruits sourced from adults held in control conditions and also not expected if transgenerational acclimation confers resistance to offspring exposed to elevated temperatures. Recruits from adults held at $29.5{ }^{\circ} \mathrm{C}$ were smaller and had a lower Fv/Fm compared to their counterparts sourced from control parents. These recruits, which were on average smaller as planulae, were therefore unable to 'catch up' to the size of the control-sourced recruits regardless of recruitment temperature, perhaps because of an overall lower energy provision from Symbiodiniaceae (i.e. as suggested by their lower Fv/Fm). Being a small recruit on a reef can be detrimental, as risk of predation and algal overgrowth is greater for smaller corals and can ultimately lead to higher mortality (Edmunds et al. 2004; Raymundo and Maypa 2004; Vermeij 2006). Our results highlight an influential, detrimental effect of adult temperature on offspring rather than the beneficial effect expected from transgenerational acclimation. Furthermore, our experiment demonstrates the need to assess recruit performance over weeks, not days, to elucidate clear parent temperature effects.

\section{Could the lack of transgenerational acclimation be due to the thermal condition of the source reef?}

Chronic warming influences coral thermal tolerance (Howells et al. 2012; Fine et al. 2013; Silbiger et al. 2019). Owing in part to the warm effluent of the nearby nuclear plant and in part to the unique oceanographic characteristics (i.e. high frequency and magnitude upwelling) of southern Taiwan, Outlet Reef has experienced warmer than average temperatures and higher summer extremes than surrounding reefs for over three decades. There is evidence that this chronic thermal exposure has affected corals in the area. Shifts to more resistant Symbiodiniaceae have been observed across multiple coral species (Keshavmurthy et al. 2012, 2014), and thermal acclimation of P. damicornis from Nanwan Bay has been noted (Mayfield et al. 2013). The result might have been selection for corals that survive better at relatively high temperatures. If this were so, our high temperature treatment might not have been stressful enough to coral colonies to elicit a thermal conditioning effect. Moreover, thermal adaptation can limit plasticity, such that the capacity for cross-generational acclimation might have been eroded. Surprisingly, areas characterized by elevated and variable temperatures (i.e. sites thought to harbour species with high acclimation potential) may actually be most at risk because their capacity to acclimate beyond their already high upper thermal limits has been exceeded (Tomanek 2008). Evidence for reduced thermal plasticity at warm and variable intertidal/subtidal sites has been found across several marine molluscs and crustaceans (Stenseng et al. 2005; 
Gilman et al. 2006; Somero 2010) and recently in corals from variable environments (Klepac and Barshis 2020). It is therefore possible that our parent colonies, from a chronically warm and thermally variable reef, lacked the capacity for further thermal plasticity.

That being said, our experimental colonies did respond to chronic warming. We exposed them to high temperature at a time of year when they would be unlikely to experience such extremes (Fig. S6), and we did find a shift in timing of reproduction, lower planula size and number, and clear effects of parent temperature on recruit size and Fv/ Fm. These results suggest that our high temperature treatment did have some capacity to affect adult, larvae and recruits, even in a population potentially selected for thermal tolerance.

\section{Conclusions}

We found that the thermal environment of parent colonies has implications for adult corals as well as planulae and recruits. Thermal conditioning of adults led to smaller planulae, smaller recruit size and reduced symbiont photochemical performance associated with recruits. There was no evidence of improved offspring performance (i.e. higher survival) that would suggest enhanced resistance as a result of transgenerational acclimation. We did not assess other components of the coral holobiont (e.g. influence of Symbiodinouim, bacteria, or viruses; see Torda et al. 2017) that could affect planula and recruit growth and survival. We also examined a single generational effect of adult conditioning, which might be insufficient to comprehensively document the capacity for epigenetic effects over the long term (Donelson et al. 2018). Nevertheless, for transgenerational acclimation to offer hope for coral persistence, its effects need to be large, positive and relatively rapid. Our results suggest that this is not the case, at least for the species and conditions we examined.

By focusing mainly on demographic responses of the filial generation, we have provided a simple and relatively cost-effective method to probe for transgenerational acclimation potential without the need to commit to highly technical physiological and molecular techniques. It is likely that the responses of corals to thermal conditioning are variable across species and regions and it may be fruitful to explore this diversity in situations where the ecological costs of collection and experimentation do not outweigh the benefits (i.e. with a small sample size of colonies sourced from healthy natural populations, aquarium-based populations, or within existing restoration projects). The idea of using transgenerational acclimation to 'save coral reefs' is polarizing (Braverman 2016; Abelson 2020). However, the slow progress made in tackling the root cause of coral loss, i.e. climate change (HoeghGuldberg et al. 2017; Hughes et al. 2017b) and the inevitable committed warming of the ocean, even under optimistic emissions scenarios, seem to justify a diversity of efforts to explore how to enhance coral resilience.

Supplementary InformationThe online version contains supplementary material available at https://doi.org/10.1007/s00338021-02123-9.

Acknowledgements Thank you to Lorraine Bowes-McRae, Ken McRae and Trevor Padgett for helping to set up the experimental system and Chih-Jui (Ray) Tan for dive assistance. The manuscript was improved by feedback from Hannah Watkins, Nicola Smith, Jillian Dunic, Jordan Hollarsmith, Helen Yan and Em Lim. Funding was provided by the Taiwan Ministry of Science and Technology (to Tung-Yung Fan, MOST 107-2611-M-291-004) and the Natural Sciences and Engineering Research Council of Canada (to Crystal McRae, PGSD-489506). Thank you to Kenting National park for our coral collection permit (\# 1050002277). Lastly, thank you to two anonymous reviewers for their helpful comments, feedback and valuable time.

\section{Declarations}

Conflict of interest On behalf of all authors, the corresponding author states that there is no conflict of interest.

Open Access This article is licensed under a Creative Commons Attribution 4.0 International License, which permits use, sharing, adaptation, distribution and reproduction in any medium or format, as long as you give appropriate credit to the original author(s) and the source, provide a link to the Creative Commons licence, and indicate if changes were made. The images or other third party material in this article are included in the article's Creative Commons licence, unless indicated otherwise in a credit line to the material. If material is not included in the article's Creative Commons licence and your intended use is not permitted by statutory regulation or exceeds the permitted use, you will need to obtain permission directly from the copyright holder. To view a copy of this licence, visit http://creativecommons. org/licenses/by/4.0/.

\section{References}

Abelson A (2020) Are we sacrificing the future of coral reefs on the altar of the "climate change" narrative? ICES J Mar Sci 77:40-45

Agostinelli C, Lund U (2017) R package 'circular': Circular Statistics (version 0.4-93). https://r-forge.r-project.org/projects/circular/

Albright R, Mason B (2013) Projected near-future levels of temperature and $\mathrm{pCO} 2$ reduce coral fertilization success. PLoS ONE 8:e56468. https://doi.org/10.1371/journal.pone.0056468

Anlauf H, D'Croz L, O'Dea A (2011) A corrosive concoction: the combined effects of ocean warming and acidification on the early growth of a stony coral are multiplicative. J Exp Mar Bio Ecol 397:13-20

Barton K (2009) MuMIn: multi-model inference. http://R-Forge.Rproject.org/projects/mumin/

Bates D, Maechler M, Bolker B, Walker S (2015) Fitting linear mixed-effects models using lme4. J Stat Softw 67:1-48

Bellwood DR, Hughes TP, Folke C, Nyström M (2004) Confronting the coral reef crisis. Nature 429:827-833 
Bellworthy J, Menoud M, Krueger T, Meibom A, Fine M (2019) Developmental carryover effects of ocean warming and acidification in corals from a potential climate refugium, the Gulf of Aqaba. J Exp Biol 222: jeb186940. https://doi.org/10.1242/jeb. 186940

Brady AK, Hilton JD, Vize PD (2009) Coral spawn timing is a direct response to solar light cycles and is not an entrained circadian response. Coral Reefs 28:677-680

Braverman I (2016) Biopolarity: coral scientists between hope and despair. Anthropol Now 8:26-40

Brown BE, Dunne RP, Phongsuwan N, Patchim L, Hawkridge JM (2014) The reef coral Goniastrea aspera: a 'winner' becomes a 'loser' during a severe bleaching event in Thailand. Coral Reefs 33:395-401

Bruno JF, Selig ER (2007) Regional decline of coral cover in the Indo-Pacific: timing, extent and subregional comparisons. PLoS ONE 2:e711. https://doi.org/10.1371/journal.pone.0000711

Burke L, Reytar K, Spalding M, Perry A (2011) Reefs at risk revisited. World Resources Institute

Byrne M, Foo SA, Ross PM, Putnam HM (2020) Limitations of crossand multigenerational plasticity for marine invertebrates faced with global climate change. Glob Chang Biol 26:80-102

Cantin NE, Cohen AL, Karnauskas KB, Tarrant AM, McCorkle DC (2010) Ocean warming slows coral growth in the central Red Sea. Science 329:322-325

Carballo-Bolaños R, Soto D, Chen CA (2020) Thermal stress and resilience of corals in a climate-changing world. J Mar Sci Eng 8:15. https://doi.org/10.3390/jmse8010015

Carpenter KE, Abrar M, Aeby G, Aronson RB, Banks S, Bruckner A, Chiriboga A, Cortés J, Delbeek JC, DeVantier L, Edgar GJ (2008) One-third of reef-building corals face elevated extinction risk from climate change and local impacts. Science 321:560-563

Charnov EL, Ernest SM (2006) The offspring-size/clutch-size tradeoff in mammals. Am Nat 167:578-582

Chua CM, Leggat W, Moya A, Baird AH (2013) Temperature affects the early life history stages of corals more than near future ocean acidification. Mar Ecol Prog Ser 475:85-92

Côté IM, Knowlton N (2013) Coral reef ecosystems: A decade of discoveries. Marine Community Ecology and Conservation (Bertness M, Bruno J, Silliman B, Stachowicz J, eds), 299-314, Sinauer: Sunderland

Cox EF, Ward S (2002) Impact of elevated ammonium on reproduction in two Hawaiian scleractinian corals with different life history patterns. Mar Pollut Bull 44:1230-1235

Craggs J, Guest J, Davis M, Sweet M (2020) Completing the life cycle of a broadcast spawning coral in a closed mesocosm. Invertebra Reprod Devel 29:1-4

Crowder CM, Liang WL, Weis VM, Fan TY (2014) Elevated temperature alters the lunar timing of planulation in the brooding coral Pocillopora damicornis. PLoS ONE 9:e107906. https://doi. org/10.1371/journal.pone.0107906

Cumbo VR, Fan TY, Edmunds PJ (2012) Physiological development of brooded larvae from two pocilloporid corals in Taiwan. Mar Biol 159:2853-2866

Cumbo VR, Edmunds PJ, Wall CB, Fan TY (2013) Brooded coral larvae differ in their response to high temperature and elevated pCO 2 depending on the day of release. Mar Biol 160:2903-2917

de Putron SJ, Lawson JM, White KQ, Costa MT, Geronimus MV, MacCarthy A (2017) Variation in larval properties of the Atlantic brooding coral Porites astreoides between different reef sites in Bermuda. Coral Reefs 36:383-393

Donelson JM, Salinas S, Munday PL, Shama LN (2018) Transgenerational plasticity and climate change experiments: Where do we go from here? Glob Chang Biol 24:13-34
Eakin CM, Sweatman HP, Brainard RE (2019) The 2014-2017 global-scale coral bleaching event: insights and impacts. Coral Reefs 38:539-545

Edmunds PJ, Bruno JF, Carlon DB (2004) Effects of depth and microhabitat on growth and survivorship of juvenile corals in the Florida Keys. Mar Ecol Prog Ser 278:115-124

Edmunds PJ (2008) The effects of temperature on the growth of juvenile scleractinian corals. Mar Biol 154:153-162

Edmunds PJ, Cumbo V, Fan TY (2011) Effects of temperature on the respiration of brooded larvae from tropical reef corals. J Exp Biol 214:2783-2790

Fan TY, Lin KH, Kuo FW, Soong K, Liu LL, Fang LS (2006) Diel patterns of larval release by five brooding scleractinian corals. Mar Ecol Prog Ser 321:133-142

Fan TY, Hsieh YC, Lin KH, Kuo FW, Soong K, McRae CJ, Edmunds PJ, Fang LS (2017) Plasticity in lunar timing of larval release of two brooding pocilloporid corals in an internal tide-induced upwelling reef. Mar Ecol Prog Ser 569:117-127

Figueiredo J, Baird AH, Harii S, Connolly SR (2014) Increased local retention of reef coral larvae as a result of ocean warming. Nat Clim Change 4:498-502

Fine M, Gildor H, Genin A (2013) A coral reef refuge in the Red Sea. Glob Chang Biol 19:3640-3647

Fitt WK, Brown BE, Warner ME, Dunne RP (2001) Coral bleaching: interpretation of thermal tolerance limits and thermal thresholds in tropical corals. Coral Reefs 20:51-65

Fox J, Weisberg S (2019) An R Companion to Applied Regression, Third Edition. Thousand Oaks CA: Sage. https://socialsciences. mcmaster.ca/jfox/Books/Companion

Frieler K, Meinshausen M, Golly A, Mengel M, Lebek K, Donner SD, Hoegh-Guldberg $\mathrm{O}$ (2013) Limiting global warming to $2{ }^{\circ} \mathrm{C}$ is unlikely to save most coral reefs. Nat Clim Change 3:165-170

Gilman SE, Wethey DS, Helmuth B (2006) Variation in the sensitivity of organismal body temperature to climate change over local and geographic scales. PNAS 103:9560-9565

Grottoli AG, Rodrigues LJ, Juarez C (2004) Lipids and stable carbon isotopes in two species of Hawaiian corals, Porites compressa and Montipora verrucosa, following a bleaching event. Mar Biol 145:621-631

Grottoli AG, Rodrigues LJ, Palardy JE (2006) Heterotrophic plasticity and resilience in bleached corals. Nature 440:1186-1189

Grottoli AG, Warner ME, Levas SJ, Aschaffenburg MD, Schoepf V, McGinley M, Baumann J, Matsui Y (2014) The cumulative impact of annual coral bleaching can turn some coral species winners into losers. Glob Chang Biol 20:3823-3833

Harrison PL, Dubinsky Z, Stambler N (2011) Coral reefs: an ecosystem in transition. Sexual Reproduction of Scleractinian Corals. Springer, Dordrecht 59-85

Heyward AJ, Negri AP (2010) Plasticity of larval pre-competency in response to temperature: observations on multiple broadcast spawning coral species. Coral Reefs 29:631-636

Ho DH, Burggren WW (2010) Epigenetics and transgenerational transfer: a physiological perspective. J Exp Biol 213:3-16

Hoegh-Guldberg O (1999) Climate change, coral bleaching and the future of the world's coral reefs. Mar Freshw Res 50:839-866

Hoegh-Guldberg O, Mumby PJ, Hooten AJ, Steneck RS, Greenfield P, Gomez E, Harvell CD, Sale PF, Edwards AJ, Caldeira K, Knowlton N (2007) Coral reefs under rapid climate change and ocean acidification. Science 318:1737-1742

Hoegh-Guldberg O, Poloczanska ES, Skirving W, Dove S (2017) Coral reef ecosystems under climate change and ocean acidification. Front Mar Sci 4:158. https://doi.org/10.3389/fmars.2017. 00158

Hofmann GE, Todgham AE (2010) Living in the now: physiological mechanisms to tolerate a rapidly changing environment. Annu Rev Physiol 72:127-145 
Howells EJ, Beltran VH, Larsen NW, Bay LK, Willis BL, Van Oppen MJH (2012) Coral thermal tolerance shaped by local adaptation of photosymbionts. Nat Clim Change 2:116-120

Howells EJ, Abrego D, Meyer E, Kirk NL, Burt JA (2016a) Host adaptation and unexpected symbiont partners enable reef-building corals to tolerate extreme temperatures. Glob Chang Biol 22(8):2702-2714

Howells EJ, Ketchum RN, Bauman AG, Mustafa Y, Watkins KD, Burt JA (2016b) Species-specific trends in the reproductive output of corals across environmental gradients and bleaching histories. Mar Pollut Bull 105:532-539

Hughes TP, Barnes ML, Bellwood DR, Cinner JE, Cumming GS, Jackson JB, Kleypas J, van De Leemput IA, Lough JM, Morrison TH, Palumbi SR (2017a) Coral reefs in the Anthropocene. Nature 546:82-90

Hughes TP, Kerry JT, Álvarez-Noriega M, Álvarez-Romero JG, Anderson KD, Baird AH, Babcock RC, Beger M, Bellwood DR, Berkelmans R, Bridge TC (2017b) Global warming and recurrent mass bleaching of corals. Nature 543:373-377

Hughes TP, Anderson KD, Connolly SR, Heron SF, Kerry JT, Lough JM, Baird AH, Baum JK, Berumen ML, Bridge TC, Claar DC (2018) Spatial and temporal patterns of mass bleaching of corals in the Anthropocene. Science 359:80-83

Hung TC, Huang CC, Shao KT (1998) Ecological survey of coastal water adjacent to nuclear power plants in Taiwan. Chem Ecol 15:129-142

Iglesias-Prieto R, Matta JL, Robins WA, Trench RK (1992) Photosynthetic response to elevated temperature in the symbiotic dinoflagellate Symbiodinium microadriaticum in culture. Proc Natl Acad Sci 89:10302-10305

IPCC (2019) Summary for Policymakers. In: IPCC Special Report on the Ocean and Cryosphere in a Changing Climate [H.- O. Pörtner, D.C. Roberts, V. Masson-Delmotte, P. Zhai, M. Tignor, E. Poloczanska, K. Mintenbeck, M. Nicolai, A. Okem, J. Petzold, B. Rama, N. Weyer (eds.)]. In press

Isomura N, Nishihira M (2001) Size variation of planulae and its effect on the lifetime of planulae in three pocilloporid corals. Coral Reefs 20:309-315

Jan S, Chen CTA, Tu YY, Tsai HS (2004) Physical properties of thermal plumes from a nuclear power plant in the southernmost Taiwan. J Mar Sci Technol 12:433-441

Jones RJ, Ward S, Amri AY, Hoegh-Guldberg O (2000) Changes in quantum efficiency of Photosystem II of symbiotic dinoflagellates of corals after heat stress and of bleached corals sampled after the 1998 Great Barrier Reef mass bleaching event. Mar Freshw Res 51:63-71

Kassambara A, Kosinski M, Biecek P (2019) survminer: drawing survival curves using 'ggplot2'. R package version 0.4.6. https:// CRAN.R-project.org/package $=$ survminer

Kuznetsova A, Brockhoff PB, Christensen RHB (2017) lmerTest package: tests in linear mixed effects models. J Stat Softw $82: 1-26$

Klepac CN, Barshis DJ (2020) Reduced thermal tolerance of massive coral species in a highly variable environment. Proc Royal Soc b 287:20201379.

Keshavmurthy S, Hsu CM, Kuo CY, Meng PJ, Wang JT, Chen CA (2012) Symbiont communities and host genetic structure of the brain coral Platygyra verweyi, at the outlet of a nuclear power plant and adjacent areas. Mol Ecol 21:4393-4407

Keshavmurthy S, Meng PJ, Wang JT, Kuo CY, Yang SY, Hsu CM, Gan CH, Dai CF, Chen CA (2014) Can resistant coralSymbiodinium associations enable coral communities to survive climate change? A study of a site exposed to long-term hot water input. PeerJ. https://doi.org/10.7717/peerj.327

Kopp C, Domart-Coulon I, Barthelemy D, Meibom A (2016) Nutritional input from dinoflagellate symbionts in reef-building corals is minimal during planula larval life stage. Sci Adv. https://doi.org/10.1126/sciadv.1500681

Lee HJ, Chao SY, Fan KL, Wang YH, Liang NK (1997) Tidally induced upwelling in a semi-enclosed basin: Nan Wan Bay. J Oceanogr 53:467-480

Lin CH, Nozawa Y (2017) Variability of spawning time (lunar day) in Acropora versus merulinid corals: a 7-yr record of in situ coral spawning in Taiwan. Coral Reefs 36:1269-1278

Loya Y, Sakai K, Yamazato K, Nakano Y, Sambali H, van Woesik R (2001) Coral bleaching: the winners and the losers. Ecol Lett 4:122-131

Matz MV, Treml EA, Aglyamova GV, Bay LK (2018) Potential and limits for rapid genetic adaptation to warming in a Great Barrier Reef coral. PLoS Genet 14(4). https://doi.org/10.1371/journal. pgen. 1007220

Mayfield AB, Fan TY, Chen CS (2013) Physiological acclimation to elevated temperature in a reef-building coral from an upwelling environment. Coral Reefs 32:909-921

McClanahan TR, Weil E, Cortés J, Baird AH, Ateweberhan M (2009) Consequences of coral bleaching for sessile reef organisms. Coral bleaching. Springer, Berlin, Heidelberg, pp 121-138

McManus LC, Vasconcelos VV, Levin SA, Thompson DM, Kleypas JA, Castruccio FS, Curchitser EN, Watson JR (2019) Extreme temperature events will drive coral decline in the Coral Triangle. Glob Chang Biol 26:2120-2133

Negri AP, Marshall PA, Heyward AJ (2007) Differing effects of thermal stress on coral fertilization and early embryogenesis in four Indo Pacific species. Coral Reefs 26:759-763

Nozawa Y, Harrison PL (2007) Effects of elevated temperature on larval settlement and post-settlement survival in scleractinian corals, Acropora solitaryensis and Favites chinensis. Mar Biol 152:1181-1185

Nyström M, Folke C, Moberg F (2000) Coral reef disturbance and resilience in a human-dominated environment. Trends Ecol Evol 15(10):413-417

Oliver TA, Palumbi SR (2011) Do fluctuating temperature environments elevate coral thermal tolerance? Coral Reefs 30:429-440

Palumbi SR, Barshis DJ, Traylor-Knowles N, Bay RA (2014) Mechanisms of reef coral resistance to future climate change. Science 344:895-898

Pandolfi JM, Connolly SR, Marshall DJ, Cohen AL (2011) Projecting coral reef futures under global warming and ocean acidification. Science 333:418-422

Paxton CW, Baria MVB, Weis VM, Harii S (2016) Effect of elevated temperature on fecundity and reproductive timing in the coral Acropora digitifera. Zygote 24:511-516

Putnam HM, Edmunds PJ, Fan TY (2008) Effect of temperature on the settlement choice and photophysiology of larvae from the reef coral Stylophora pistillata. Biol Bull 215:135-142

Putnam HM, Edmunds PJ, Fan TY (2010) Effect of a fluctuating thermal regime on adult and larval reef corals. Invert Biol 129:199-209

Putnam HM, Gates RD (2015) Preconditioning in the reef-building coral Pocillopora damicornis and the potential for trans-generational acclimatization in coral larvae under future climate change conditions. J Exp Biol 218:2365-2372

Putnam HM, Barott KL, Ainsworth TD, Gates RD (2017) The vulnerability and resilience of reef-building corals. Curr Biol 27:528-540

Putnam HM, Ritson-Williams R, Cruz JA, Davidson JM, Gates RD (2020) Environmentally-induced parental or developmental conditioning influences coral offspring ecological performance. Sci Rep 10:13664.

R Core Team (2019) R: A language and environment for statistical computing. R Foundation for Statistical Computing, Vienna, Austria. https://www.R-project.org/ 
Randall CJ, Szmant AM (2009) Elevated temperature reduces survivorship and settlement of the larvae of the Caribbean scleractinian coral, Favia fragum (Esper). Coral Reefs 28:537-545

Raymundo LJ, Maypa AP (2004) Getting bigger faster: mediation of size-specific mortality via fusion in juvenile coral transplants. Ecol Appl 14:281-295

Richmond RH (1987) Energetics, competency and long-distance dispersal of planula larvae of the coral Pocillopora damicornis. Mar Biol 93:527-533

Rivest EB, Hofmann GE (2015) Effects of temperature and pCO2 on lipid use and biological parameters of planulae of Pocillopora damicornis. J Exp Mar Bio Ecol 473:43-52

Rodrigues LJ, Grottoli AG, Pease TK (2008) Lipid class composition of bleached and recovering Porites compressa Dana, 1846 and Montipora capitata Dana, 1846 corals from Hawaii. Journal of J Exp Mar Bio Ecol 358:136-143

Safaie A, Silbiger NJ, McClanahan TR, Pawlak G, Barshis DJ, Hench JL, Rogers JS, Williams GJ, Davis KA (2018) High frequency temperature variability reduces the risk of coral bleaching. Nat Commun 9:1-12

Sato M (1985) Mortality and growth of juvenile coral Pocillopora damicornis (Linnaeus). Coral Reefs 4:27-33

Shlesinger T, Loya Y (2019) Breakdown in spawning synchrony: A silent threat to coral persistence. Science 365:1002-1007

Silbiger NJ, Goodbody-Gringley G, Bruno JF, Putnam HM (2019) Comparative thermal performance of the reef-building coral Orbicella franksi at its latitudinal range limits. Mar Biol 166:126.

Smith HA, Moya A, Cantin NE, van Oppen MJ, Torda G (2019) Observations of simultaneous sperm release and larval planulation suggest reproductive assurance in the coral Pocillopora acuta. Front Mar Sci 6:362.

Somero GN (2010) The physiology of climate change: how potentials for acclimatization and genetic adaptation will determine "winners" and "losers." J Exp Biol 213:912-920

Stenseng E, Braby CE, Somero GN (2005) Evolutionary and acclimation-induced variation in the thermal limits of heart function in congeneric marine snails (genus Tegula): implications for vertical zonation. Biol Bull 208:138-144

Tew KS, Leu MY, Wang JT, Chang CM, Chen CC, Meng PJ (2014) A continuous, real-time water quality monitoring system for the coral reef ecosystems of Nanwan Bay, Southern Taiwan. Mar Pollut Bull 85:641-647
Therneau T (2015) A package for survival analysis in S. Version 2.38. https://CRAN.R-project.org/package=survival

Terry M. Therneau (2020) coxme: mixed effects cox models. R package version 2.2-16. https://CRAN.R-project.org/package= coxme

Tomanek L (2008) The importance of physiological limits in determining biogeographical range shifts due to global climate change: the heat-shock response. Physiol Biochem Zool 81:709-717

Torda G, Donelson JM, Aranda M, Barshis DJ, Bay L, Berumen ML, Bourne DG, Cantin N, Foret S, Matz M, Miller DJ (2017) Rapid adaptive responses to climate change in corals. Nat Clim Chang 7:627-636

van Oppen MJ, Oliver JK, Putnam HM, Gates RD (2015) Building coral reef resilience through assisted evolution. Proc Natl Acad Sci 112:2307-2313

van Oppen MJ, Gates RD, Blackall LL, Cantin N, Chakravarti LJ, Chan WY, Cormick C, Crean A, Damjanovic K, Epstein H, Harrison PL (2017) Shifting paradigms in restoration of the world's coral reefs. Glob Chang Biol 23:3437-3448

van Woesik R (2010) Calm before the spawn: global coral spawning patterns are explained by regional wind fields. Proc R Soc Lond B Biol Sci 277:715-722

van Woesik R, Sakai K, Ganase A, Loya Y (2011) Revisiting the winners and the losers a decade after coral bleaching. Mar Ecol Prog Ser 434:67-76

Vermeij MJA (2006) Early life-history dynamics of Caribbean coral species on artificial substratum: the importance of competition, growth and variation in life-history strategy. Coral Reefs 25:59-71

Wilkinson CR (1998) Status of coral reefs of the world, 1998. Published on behalf of the Global Coral Reef Monitoring Network, Australian Institute of Marine Science

Woodhead AJ, Hicks CC, Norström AV, Williams GJ, Graham NA (2019) Coral reef ecosystem services in the Anthropocene. Funct Ecol 33:1023-1034

Yeoh SR, Dai CF (2010) The production of sexual and asexual larvae within single broods of the scleractinian coral, Pocillopora damicornis. Mar Biol 157:351-359

Publisher's Note Springer Nature remains neutral with regard to jurisdictional claims in published maps and institutional affiliations. 